IdeAs

Idées d'Amériques

Poètes et éditeurs : diffuser la poésie d'avant-garde américaine (depuis 1945)

\title{
Juan Martin Guevara et Armelle Vincent, Mon frère le Che (Mi hermano el Che)
}

Paris (Madrid), Calmann-Lévy (Alianza Editorial), 2016, 333p. (348 p.)

\section{Alvar De la Llosa}

\section{OpenEdition \\ Journals}

Édition électronique

URL : https://journals.openedition.org/ideas/1934

DOI : $10.4000 /$ ideas. 1934

ISSN : $1950-5701$

Éditeur

Institut des Amériques

\section{Référence électronique}

Alvar De la Llosa, « Juan Martin Guevara et Armelle Vincent, Mon frère le Che (Mi hermano el Che) »,

IdeAs [En ligne], 9 | 2017, mis en ligne le 12 juillet 2017, consulté le 19 octobre 2022. URL : http:// journals.openedition.org/ideas/1934 ; DOI : https://doi.org/10.4000/ideas.1934

Ce document a été généré automatiquement le 19 octobre 2022.

\section{(c) $(1) \odot$}

Creative Commons - Attribution - Pas d'Utilisation Commerciale - Pas de Modification 4.0 International - CC BY-NC-ND 4.0

https://creativecommons.org/licenses/by-nc-nd/4.0/ 


\title{
Juan Martin Guevara et Armelle Vincent, Mon frère le Che (Mi hermano el Che)
}

Paris (Madrid), Calmann-Lévy (Alianza Editorial), 2016, 333p. (348 p.)

\author{
Alvar De la Llosa
}

\section{RÉFÉRENCE}

Juan Martin Guevara et Armelle Vincent, Mon frère le Che (Mi hermano el Che), Paris

(Madrid), Calmann-Lévy (Alianza Editorial), 2016, 333p. (348 p.)

1 Jorge Semprun racontait que, clandestin du Parti communiste espagnol sous la dictature de Franco, il vivait avec un ouvrier qui avait mille aventures et anecdotes à relater, de sa jeunesse au présent en passant par la Guerre d'Espagne, mais que, malheureusement, il lui manquait l'art littéraire pour bien les raconter, les mettre en valeur. On ne peut faire ce reproche à Guevara et Vincent.

2 Le premier est le frère d'un certain Ernesto Che Guevara, passé à la postérité pour les raisons que l'on sait, assassiné en octobre 1967 par la CIA en Bolivie où il tentait, par une action révolutionnaire improbable, de desserrer l'étau qui entourait Cuba en cette époque de vietnamisation du sous-continent, deux ans après le débarquement des Marines en République dominicaine. Il est aussi et surtout un témoin de son époque une époque argentine marquée par des crises économiques, etdes coups d'État qui suivent chaque réveil des forces populaires, un passé de militant du Partido Revolucionario de los Trabajadores et - et ce n'est pas rien -8 ans, 3 mois et 23 jours d'incarcération continue dans les geôles de la dernière dictature militaire argentine.

Verve, truculence et expressions populaires sont, tout autant que l'humour (ironie et autodérision) rendus par la traduction et l'écriture d'Armelle Vincent quiest correspondante de plusieurs journaux français, dont Le Figaro à Los Angeles. Rencontre improbable entre deux personnages qui, semble-t-il s'est faite autour... de cette 
excellente chose qu'est le tabac, notamment quand il s'agit de... havanes... Tout cela ne constitue qu'une partie de la réussite de l'ouvrage. Car on n'est pas devant une simple (ennuyeuse) et énième évocation du Che, en cette année anniversaire, mais devant un ouvrage qui dépasse son sujet en le replaçant dans un contexte plus large qui va de l'anecdote familiale à ce culte ridicule (« répugnant », « Business touristique », « d'une bassesse inouïe ») fait de marchandisation et de religiosité, jusqu'à l'histoire récente de l'Argentine.

4 Juan Martín, qui a gardé le silence pendant cinquante ans, explique la raison de son ouvrage : combattre le mythe « en redonnant à mon frère un visage humain ». Un frère de quinze ans son aîné et un mythe né en moins de onze ans (1956-1967) qui perdure depuis cinquante ans. L'auteur fait ainsi part de la difficulté, à 73 ans, alors qu'il ne l'a jamais évoqué, de parler d'un frère qui a beaucoup représenté et qui est disparu trop tôt. Toute la famille souffrira du nom porté, et le cachera. Au-delà d'une histoire du Che, c'est l'histoire d'une famille condamnée au silence à cause d'un nom évocateur de trop de rébellion. Dès 1963, la mère est condamnée à deux mois de prison, dans une Argentine encore "démocratique», parce qu'elle revient de Cuba. Accusée d'espionnage, elle n'est libérée que parce qu'elle accepte d'être expulsée de son propre pays. De 1957 à 1983, « être un parent du Che représentait un danger ». Seul l'asile et le soutien sans faille de Castro permettra d'échapper au génocide.

On ne doit pas attendre une critique à l'égard d'un frère qui était pour lui un héros bien avant de devenir le Che. À cet égard, l'auteur distingue une époque avant le Che et une après le Che dans l'histoire de la famille. Sans doute ce distinguo peut être repris pour l'histoire de l'Amérique contemporaine. L'évocation du milieu familial bohème et libéral, où l'on discute et on argumente, éclaire sur le personnage, sa formation et son caractère. Il permet de renseigner définitivement et d'en finir avec les légendes, notamment celle d'une supposée famille de la haute bourgeoisie membre de l'oligarchie créole, alors qu'elle est désargentée à l'extrême suite à la crise de 1929, comme beaucoup de classes moyennes argentines qui ont irrémédiablement dévalé la pente financière. C'est aussi un témoignage de la vie des classes moyennes et populaires qui retient l'attention. Le souvenir de l'éducation reçue fait comprendre l'individu qui deviendra personnage historique. Éducation réalisée en grande partie par une mère engagée en faveur de la République espagnole en armes puis de la France libre. Une mère intellectuelle élevée chez les sœurs françaises du Sacré-Cœur, qui enseigne le français à son fils. Puis les voyages sans argent à travers l'Argentine et l'Amérique latine forgent une conscience politique née de la connaissance directe des phénomènes sociaux et des mécanismes d'exploitation. Les anecdotes rendent compte d'une époque et offrent une sociologie de l'Argentine passée. Elles éclairent le personnage, notamment sa propension à un culte épistolier stalinien, auquel il a été prêté trop d'importance alors qu'il n'est qu'une manière juvénile de faire gentiment enrager une tante très conservatrice.

6 On apprécie les pages évoquant la vie dans les années 1950, charnière où l'on observe le comportement de ces classes moyennes appauvries qui possèdent une formation politique, mais qui se trouvent désemparées face au phénomène inattendu et inédit de Perón, ce qui conduit,a posteriori, à une excellente caractérisation sans concession du péronisme (p. 117, 202). L'œuvre apporte un éclairage intéressant sur les modes de militantisme des années 60 , l'importance que revêt encore le PCA, la rupture qu'induit l'expérience cubaine au sein de la gauche traditionnelle et immobile, et comment la 
répression des divers régimes militaires argentins des années 1960 conduit les militants de la gauche classique à privilégier l'option de la lutte armée, tout en provoquant, dans les années 1970, des réticences à la pratiquer, de crainte de déclencher une violence supérieure et irrémédiable alors même qu'il est clair que le coup d'État se profile. Elle livre aussi un portrait de la société argentine au sortir de la dictature, la peur du citoyen domestiqué, les jeunes déboussolés et l'affairisme nécessaire pour survivre.

Un tiers de l'ouvrage est consacré à la répression militaire argentine, en la resituant dans son contexte national et international, rappelant que l'horreur commence en 1974 pour devenir systématique à partir de mars 1976. L'auteur remarque, non sans ironie, qu'il doit sa survie à la chance d'être arrêté avant 1976, à une époque encore 'démocratique', et donc fiché par la Justice (ou ce qu'il en reste...). Les pages où Juan Martín évoque ses années d'enfermement (1974-1983) sous la dictature atteignent une qualité et une hauteur rarement obtenues dans l'ensemble de la littérature de la répression. Ces pages,pudiques, justes, précises, sans fioritures, sont d'une très grande retenue; témoignage brut, sans tentations fictionnelles, elles résonnent comme un appel à la mémoire plus qu'à la dénonciation. Elles sont d'une extraordinaire efficacité supérieure parce que la froideur du témoignage de celui qui les a vécues et les rédige les rendent efficaces. Elles offrent une force et une cohérence que beaucoup de pages fictionnelles de recréation littéraire de la répression n'atteignent pas. L'effacement du moi subjectif renforce cette vérité et cette universalité. Ces pages sont d'autant plus efficaces et éclairantes que l'auteur n'évoque ses souffrances que parce qu'elles sont communes à ses compagnons d'infortune.

8 Écriture du souvenir, mémoire d'une famille saccagée, mais aussi évocation historique et réflexion sur une époque, font l'intérêt de cet ouvrage qui n'a d'autre prétention que d'exposer des souvenirs pour les projeter dans l'avenir et pour expliquer les conditions privées et historiques qui ont conduit Che a être ce qu'il est devenu, bien que sa réalité soit aujourd'hui masquée par une icône marchande. À des années de distance, Juan Martín Guevara rapporte des souvenirs alors qu'à l'époque des événements, au moment où il les a vécus, il n'avait pas conscience du moment historique qui se déroulait, qu'il vivait et dont il était témoin ou acteur. Si la fin est quelque peu confuse dans sa tentative d'explication de la crise, le menant à rejeter des médias comme le Net, alors qu'il est devenu le seul vecteur dissident face à une information contrôlée par les grandes concentrations, au final, par une foule d'anecdotes, l'ouvrage renseigne sur l'époque et éclaire de façon définitive un personnage qui, qu'on le veuille ou non, audelà de toute marchandisation et $\mathrm{du}$ mythe, est une figure majeure de l'histoire de l'Amérique latine parce qu'il a concentré toutes les contradictions et les aspirations d'une époque.

\section{AUTEURS}

\section{ALVAR DE LA LLOSA}

Université Lyon 2, LCE, EA 1853 